\title{
Correlation of p16 and cyclin D1 expression with the incidence and prognosis of cardiac carcinoma
}

\author{
HAOXUN WANG ${ }^{1}$, JING WANG ${ }^{2}$ and BINGBO ZHAO ${ }^{3}$ \\ ${ }^{1}$ The Oncology Department, The Second Affiliated Hospital of Zhengzhou University, Zhengzhou, Henan 450014;
${ }^{2}$ Department of Digestive Medicine, Hospital of Traditional Chinese Medicine of Liaocheng City;
${ }^{3}$ Department of Gastrointestinal Surgery, Liaocheng People's Hospital, Liaocheng, Shandong 252000, P.R. China
}

Received June 11, 2018; Accepted February 14, 2019

DOI: $10.3892 / \mathrm{ol} .2019 .10189$

\begin{abstract}
Correlation of p16 and cyclin D1 expression with the incidence and prognosis of cardiac carcinoma was investigated. Thirty-six patients with cardiac carcinoma treated in The Second Affiliated Hospital of Zhengzhou University were selected. After the radical operation of cardiac carcinoma, carcinoma tissues were taken, and the corresponding paracarcinoma tissues were used as controls. p16 and cyclin D1 messenger ribonucleic acid (mRNA) and protein expression in cardiac carcinoma tissues and para-carcinoma tissues were detected via quantitative polymerase chain reaction (qPCR) and western blot analysis. The survival time and pathological conditions of patients with cardiac carcinoma were recorded in detail, and correlation of p16 and cyclin D1 with incidence and prognosis of cardiac carcinoma was studied. In cardiac carcinoma tissues, the p16 mRNA and protein expression levels were significantly lower than those in paracarcinoma tissues $(\mathrm{P}<0.01)$, but the cyclin D1 mRNA and protein expression levels were significantly higher than those in para-carcinoma tissues $(\mathrm{P}<0.01)$. The expression of $\mathrm{p} 16$ and cyclin D1 protein had correlation with the tumor size, lymph node metastasis and tumor-node-metastasis stage of cardiac carcinoma $(\mathrm{P}<0.01)$. There was a negative correlation between expression of p16 and cyclin D1 in cardiac carcinoma $(\mathrm{P}<0.01)$. According to Kaplan-Meier survival analysis, the survival rate of patients with high expression of p16 was obviously higher than that of patients with low expression of p16 $(\mathrm{P}<0.01)$, while the survival rate of patients with high expression of cyclin D1 was obviously lower than that of patients with low expression of cyclin D1 $(\mathrm{P}<0.01)$. Both p16 and cyclin D1 are closely related to the incidence and prognosis of cardiac carcinoma, which may become indexes for the incidence and prognosis of cardiac carcinoma.
\end{abstract}

Correspondence to: Dr Bingbo Zhao, Department of Gastrointestinal Surgery, Liaocheng People's Hospital, 67 Dongchangxi Road, Liaocheng, Shandong 252000, P.R. China

E-mail: ztup488@163.com

Key words: cardiac carcinoma, p16, cyclin D1, prognosis

\section{Introduction}

Cardiac carcinoma is a kind of malignant tumor in the cardia, which has the poorest prognosis in gastric carcinoma, seriously harming the quality of life and health of patients $(1,2)$. According to the epidemiological survey, the incidence of cardiac carcinoma shows an increasing trend year by year in China, and it has increased more than five-fold over the decades (3). It has been proven that smoking, stimulating beverages, irregular diet, gastrointestinal inflammation and gastroesophageal reflux are precipitating factors for cardiac carcinoma. Currently, surgical resection is the most effective treatment means for cardiac carcinoma, but the poor prognosis of patients is still an important reason affecting the therapeutic effect $(4,5)$.

The $p 16$ gene can inhibit the progression of a variety of tumors and encode the nucleotide protein (p16 protein) to significantly inhibit the cyclin-dependent kinase 4 (CDK4), thus playing an important role in the progression of various tumors (6). Cyclin D1, as a key cell cycle regulatory protein, can bind to CDK4/6 to form the binary complex and keep cells in $\mathrm{S}$ phase, thus promoting cell proliferation (7). Dreyer et al (8) showed that both p16 and cyclin D1 can competitively bind to CDK4, thereby regulating the occurrence and development of tumors. Feng et al (9) found that when the expression level of p16 is blocked, it leads to dominant binding between cyclin D1 and CDK4 and continuous cell proliferation, thus resulting in tumors. According to the study of $\mathrm{Pu}$ et al (10), pl6 is a predisposing gene of cardiac carcinoma, and it has been shown in several animal models that the p16 expression level in cardiac carcinoma tissues is significantly reduced. However, the correlation of p16 and cyclin D1 with incidence and prognosis of cardiac carcinoma remains unclear.

This study analyzed the p16 and cyclin D1 gene and protein expression levels in carcinoma tissues of patients with cardiac carcinoma, and aimed to clarify the correlation of their expression with the incidence and prognosis of cardiac carcinoma to provide a theoretical basis for clinical diagnosis, treatment and prognosis estimation of cardiac carcinoma.

\section{Patients and methods}

Research subjects and sampling. Patients with cardiac carcinoma who attended the Department of Gastroenterology 
of The Second Affiliated Hospital of Zhengzhou University (Zhengzhou, China) from March 2012 to March 2013 were collected, of which 36 cases (28 males, 8 females) definitely diagnosed with primary cardiac carcinoma and treated with radical operation of cardiac carcinoma were selected. The patients were aged 42-69 years with an average age of 58.6 years. According to the tumor-node-metastasis (TNM) staging system issued by the Union for International Cancer Control (UICC), there were 3 cases in stage I, 5 cases in stage II, 25 cases in stage III and 3 cases in stage IV. Inclusion criteria were: i) patients without a history of severe cardiovascular, cerebrovascular diseases and immune system disease, ii) patients without severe hepatic and renal impairment, iii) patients receiving no chemotherapy or radiotherapy before operation, iv) patients definitely diagnosed with cardiac carcinoma by pathologic examinations, and v) patients who agreed to participate in follow-up visits and finished 5-year follow-up visits.

Informed consent was signed by patients themselves or their family members. All clinical and pathological data and complete treatment schedule were preserved. The plan of this experiment was reviewed and ethically approved in The Second Affiliated Hospital of Zhengzhou University.

For sampling, cardiac carcinoma tissue was excised surgically while para-carcinoma tissue was resected at the cardia over $3 \mathrm{~cm}$ away from the edge of the cancerous tissue. Specimens of cancerous tissue and para-carcinoma tissue were partially made into paraffin sections and were definitely diagnosed by the Department of Pathology. The remaining cancerous and para-carcinoma tissue was immediately cryopreserved in liquid nitrogen and then transferred to a refrigerator at $-80^{\circ} \mathrm{C}$ for standby application.

Detection of expression levels of pl6 and cyclin D1 mRNA in cardiac carcinoma tissue and para-carcinoma tissue by quantitative polymerase chain reaction $(q P C R)$. Cardiac carcinoma tissue and para-carcinoma tissue of all the patients were weighed and added into TRIzol (Thermo Fisher Scientific, Inc., Waltham, MA, USA) at a ratio of $100 \mathrm{mg}: 1 \mathrm{ml}$. Tissues were smashed to fragments invisible to the naked eye in an ice bath using an ultrasonic homogenizer, placed on ice for $10 \mathrm{~min}$ of incubation and then centrifuged at $4{ }^{\circ} \mathrm{C}$ and $12,000 \mathrm{x} \mathrm{g}$ for $10 \mathrm{~min}$. The supernatant was collected and added with $700 \mu \mathrm{l}$ of trichloromethane, which was placed on ice for $10 \mathrm{~min}$ of incubation after repeated shaking for $10 \mathrm{sec}$, followed by centrifugation at $4^{\circ} \mathrm{C}$ and $12,000 \mathrm{x}$ g for $15 \mathrm{~min}$. The upper layer aqueous phase was collected and added with isopropanol of equal volume. After $10 \mathrm{sec}$ of repeated shaking, the mixture was centrifuged at $4^{\circ} \mathrm{C}$ and $10,000 \mathrm{x}$ for $10 \mathrm{~min}$. The mixture was washed with $1 \mathrm{ml}$ of newly-prepared $75 \%$ ethanol after the supernatant was discarded, shaken repeatedly for $10 \mathrm{sec}$ and centrifuged at $4^{\circ} \mathrm{C}$ and $12,000 \mathrm{x}$ for $10 \mathrm{~min}$. After the supernatant was discarded, the cover of the centrifuge tube was opened to make it dry naturally. RNA was obtained after $30 \mu 1$ DEPC-treated water was added. RNA concentration and purity were determined using an ultraviolet spectrophotometer. In this experiment, the absorbance (A) 260/A280 ratio of RNA was between 1.8 and 1.9 and the concentration and purity of RNA were both high. The agarose gel experiment indicated that RNA was not degraded, so it could be used
Table I. PCR primer sequences.

\begin{tabular}{lc}
\hline Gene name & \multicolumn{1}{c}{ Primers } \\
\hline p16 & F: 5'-ACCAGAGGCAGTAACCATGC-3' \\
& R: 5'-CCTGTAGGACCTTCGGTGAC-3' \\
Cyclin D1 & F:5'-ACCTGAGGAGCCCCAACAAC-3' \\
& R: 5'-GCTTCGATCTGCTCCTGGC-3' \\
GAPDH & F: 5'-CTCTGGTAAAGTGGATATTGT-3' \\
& R: 5'-GGTGGAATCATATTGGAACA-3'
\end{tabular}

F, forward; R, reverse.

in follow-up experiments. Reverse transcriptional reaction system was configured strictly according to instructions of the reverse transcription kit (Vazyme Biotech Co., Ltd., Nanjing, China). Reverse transcription was carried out after $5 \mathrm{~min}$ of reaction at $65^{\circ} \mathrm{C}$ and $2 \mathrm{~min}$ of incubation at $37^{\circ} \mathrm{C}$. qPCR system was configured strictly following instructions of qPCR kit (Vazyme Biotech Co., Ltd.), which was amplified on qPCR device. Amplification conditions were: $15 \mathrm{~min}$ of predegeneration at $95^{\circ} \mathrm{C}, 10 \mathrm{sec}$ of degeneration at $95^{\circ} \mathrm{C}$ and $32 \mathrm{sec}$ of annealing at $60^{\circ} \mathrm{C}, 40$ cycles in total. The amplification volume of p16 gene and cyclin D1 gene and that of glyceraldehyde3-phosphate dehydrogenase $(G A P D H)$ gene in all specimens were compared using $2^{-\Delta \Delta \mathrm{Cq}}(11)$. Expression levels of p16 and cyclin D1 in cardiac carcinoma and para-carcinoma tissue were presented as p16/GAPDH and cyclin D1/GAPDH and analyzed with ImageJ professional image analysis software (NIH, Bethesda, MD, USA).

The primer sequences in this experiment were produced by Invitrogen (Thermo Fisher Scientific, Inc.) and the primer sequences are shown in Table I.

Detection of p16 and cyclin D1 protein expression in cardiac carcinoma tissues and para-carcinoma tissues via western blotting. After sodium dodecyl sulphate-polyacrylamide gel (SDS-PAGE), cardiac carcinoma tissues and para-carcinoma tissues were taken, added with radioimmunoprecipitation assay (RIPA) lysis solution $(1 \mathrm{mg}: 1 \mathrm{ml})$ and then added with $1 \%$ protease inhibitor and $1 \%$ phosphatase inhibitor, followed by homogenization in an ice bath using an ultrasonic homogenizer until there were no visible tissues to the naked eye. After standing for $5 \mathrm{~min}$ in an ice bath, centrifugation was performed at $12,000 \mathrm{x} \mathrm{g}$ and $4^{\circ} \mathrm{C}$ for $10 \mathrm{~min}$. The supernatant was transferred into a new EP tube, and the total protein concentration in the sample in each group was detected using the bicinchoninic acid (BCA) protein assay kit (Pierce). The 5X SDS loading buffer and RIPA lysis solution were added to prepare the protein sample in the protein loading buffer in an equal concentration, and the protein was boiled at $95^{\circ} \mathrm{C}$ for $15 \mathrm{~min}$ for denaturation. Loading buffer $(15 \mu \mathrm{l})$ was added to each well, and $10 \%$ SDS-PAGE was performed under a constant pressure of $80 \mathrm{~V}$, after which the membrane transfer 'sandwich' was prepared. The protein was transferred onto a polyvinylidene fluoride (PVDF) membrane (IPVH00010; EMD Millipore, Billerica, MA, USA) after being soaked in methanol at low temperature and $100 \mathrm{~V}$ for $90 \mathrm{~min}$. Subsequently, the protein band was sealed 
with freshly-prepared 5\% skim milk powder at room temperature. After $1 \mathrm{~h}$, the band was cut according to the size of the target band, and rabbit anti-human p16, cyclin D1 and GAPDH monoclonal antibodies (1:1,000; cat. nos. 80772, 2978 and 2118, respectively; all obtained from Cell Signaling Technology, Inc., Danvers, MA, USA) were incubated at $4^{\circ} \mathrm{C}$ overnight. The next day, the membrane was taken, washed with Tris-buffered saline with Tween-20 (TBST) 3 times (10 min/time), incubated with the horseradish peroxidase-labeled secondary goat anti-rabbit polyclonal antibody (1:5,000; cat. no. 7074; Cell Signaling Technology, Inc.) at room temperature for $1 \mathrm{~h}$, and washed again with TBST 3 times (10 min/time). The liquid on the surface of PVDF membrane was sucked dry using the filter paper, and the enhanced chemiluminescence (ECL) solution was added (liquid $\mathrm{A}$ and $\mathrm{B}$ were mixed in an equal volume), followed by incubation in the dark for $1 \mathrm{~min}$, and image development using the gel imaging system (Bio-Rad Laboratories, Inc., Hercules, CA, USA). After the image was scanned and saved, the gray value of band was analyzed. The p16/GAPDH and cyclin D1/GAPDH represented the expression levels of p16 and cyclin D1 in cardiac carcinoma tissues and para-carcinoma tissues.

Collection of clinicopathological data and survival analysis. Various clinicopathological data, clinical data and clinical therapeutic schemes of all included patients were preserved in detail and the postoperative basic treatment for patients was consistent. Enrolled patients were divided into the low- and high-expression p16 group, and the low- and high-expression cyclin D1 group according to differences in the expression levels of p16 and cyclin D1. Patients were followed up for 5 years and relevant follow-up data were recorded, the correlation of the expression levels of p16 and cyclin D1 with prognosis was analyzed. Kaplan-Meier survival curves were plotted.

Statistical analysis. Research data are presented as mean \pm standard deviation. Statistical Product and Service Solutions (SPSS) 19.0 software (IBM Corp., Armonk, NY, USA) was used for analytical processing of data. The Chi-square test was used for analysis of enumeration data, which were tested by homogeneity test of variance. The Bonferronic method was used for pairwise comparison if variance was homogeneous, while the Welch method was conducted if not. The Students' t-test was applied for comparison between two groups and Pearson correlation analysis was performed for correlation analysis between p16 and cyclin D1. The correlation of clinicopathologic data with expression levels of p16 and cyclin D1 protein was analyzed using Fisher's precise test and survival analysis was carried out with Kaplan-Meier and log rank test. $\mathrm{P}<0.05$ was considered to indicate a statistically significant difference.

\section{Results}

Expression levels of p16 and cyclin D1 mRNA in cardiac carcinoma tissues and para-carcinoma tissues. p16 and cyclin D1 mRNA expression in cardiac carcinoma tissues and para-carcinoma tissues were detected via qPCR. Results showed that in cardiac carcinoma tissues, the p16 mRNA expression was significantly lower than that in para-carcinoma tissues $(\mathrm{P}<0.01)$, but the cyclin D1 mRNA expression was significantly higher than that in para-carcinoma tissues $(\mathrm{P}<0.01)$ (Fig. 1).
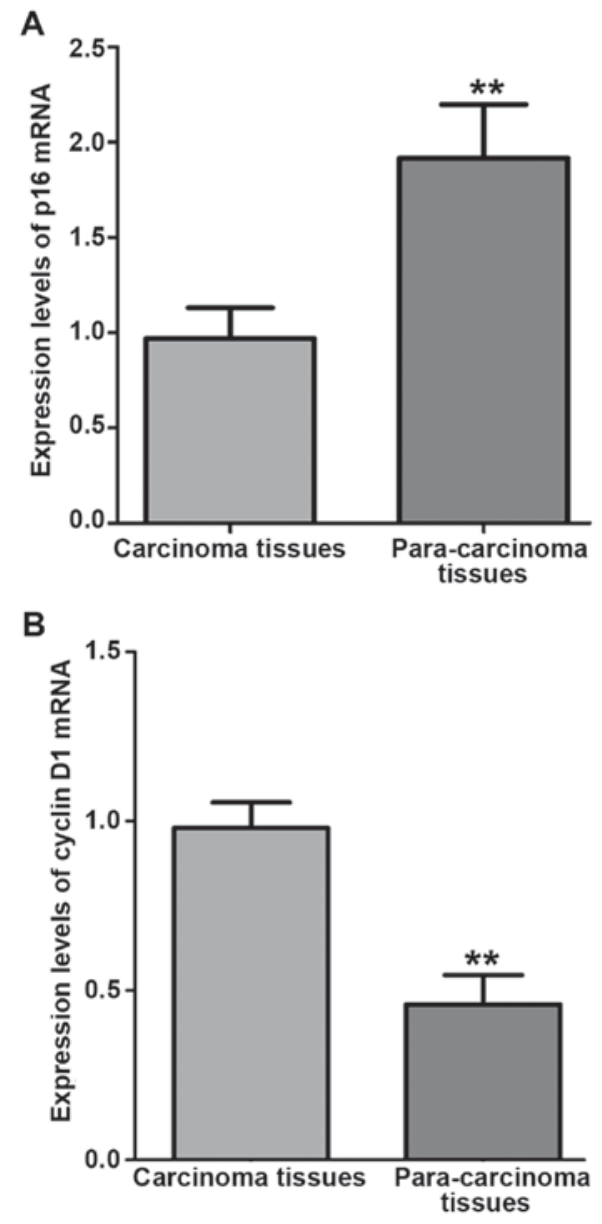

Figure 1. Expression levels of p16 and cyclin D1 mRNA in cardiac carcinoma tissues and para-carcinoma tissues. (A) Relative expression level of p16 mRNA. (B) Relative expression level of cyclin D1 mRNA. In cardiac carcinoma tissues, the p16 mRNA expression is significantly lower than that in para-carcinoma tissues, but the cyclin D1 mRNA expression is significantly higher than that in para-carcinoma tissues $\left({ }^{* *} \mathrm{P}<0.01\right)$

Expression levels of p16 and cyclin D1 proteins in cardiac carcinoma tissues and para-carcinoma tissues. p16 and cyclin D1 protein expression levels in cardiac carcinoma tissues and para-carcinoma tissues were detected via western blotting. Results revealed that in cardiac carcinoma tissues, the p16 protein expression was significantly lower than that in para-carcinoma tissues $(\mathrm{P}<0.01)$, but the cyclin D1 protein expression was significantly higher than that in para-carcinoma tissues $(\mathrm{P}<0.01)$ (Fig. 2).

Correlation analysis between p16 and cyclin D1 in cardiac carcinoma tissues. The correlation between p16 and cyclin D1 protein expression in cardiac carcinoma tissues was analyzed. Results demonstrated that there was a negative correlation between p16 and cyclin D1 protein expression in cardiac carcinoma tissues $\left(\mathrm{r}^{2}=0.2751, \mathrm{P}<0.01\right)$ (Fig. 3).

Correlation of p16 and cyclin D1 protein expression levels with clinicopathological factors of patients with cardiac carcinoma. The clinicopathological data of patients with cardiac carcinoma were recorded in detail, and their correlations with relative expression levels of p16 and cyclin D1 protein were analyzed. The relative expression levels of p16 and cyclin D1 


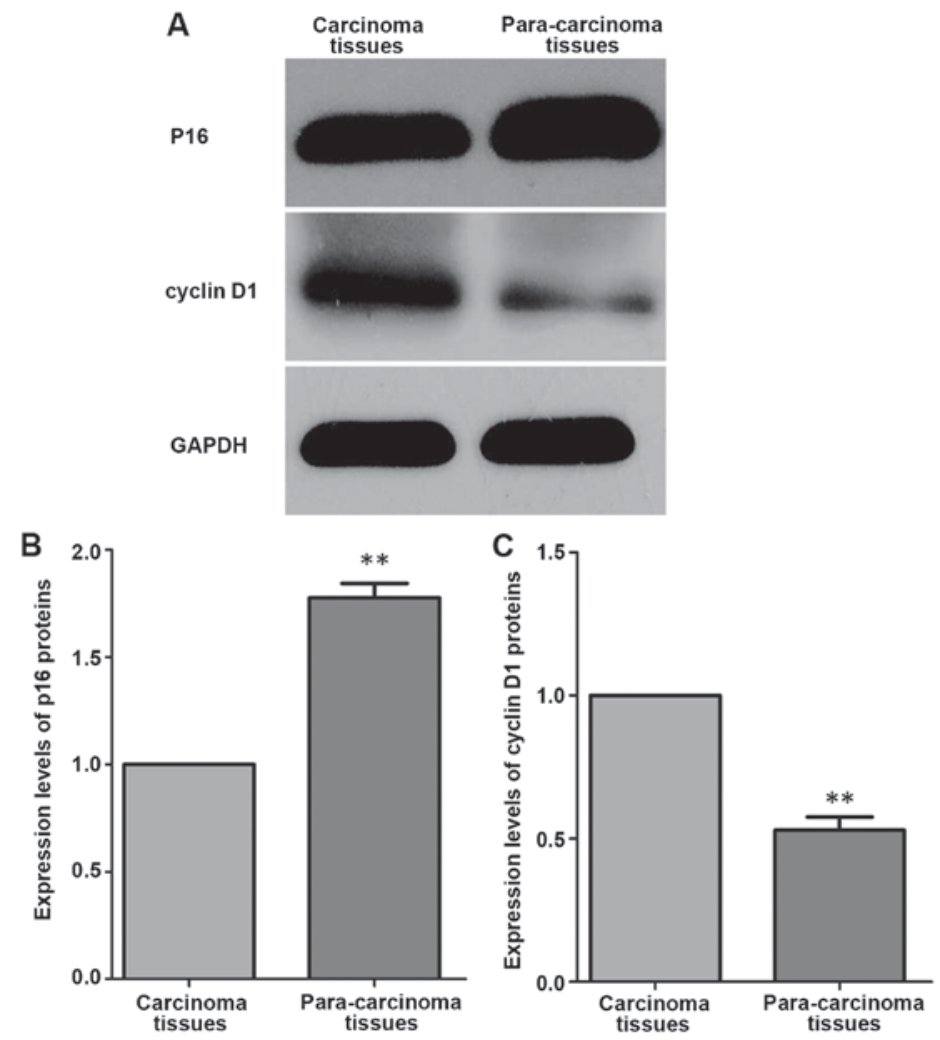

Figure 2. Expression levels of p16 and cyclin D1 proteins in cardiac carcinoma tissues and para-carcinoma tissues. (A) Band diagram. (B) Statistical graph of p16 protein expression level. (C) Statistical graph of cyclin D1 protein expression level. In cardiac carcinoma tissues, the p16 protein expression is significantly lower than that in para-carcinoma tissues, but the cyclin D1 protein expression is significantly higher than that in para-carcinoma tissues $\left({ }^{* *} \mathrm{P}<0.01\right)$.

Table II. Correlation of relative expression levels of p16 and cyclin D1 with clinicopathological factors of patients with cardiac carcinoma.

\begin{tabular}{|c|c|c|c|c|c|}
\hline Pathological detail & $\mathrm{n}$ & Relative expression level of p16 & P-value & Relative expression level of cyclin D1 & P-value \\
\hline Carcinoma tissue & 36 & $1.08 \pm 0.12$ & \multirow[t]{2}{*}{$<0.01$} & $0.83 \pm 0.15$ & \multirow[t]{2}{*}{$<0.01$} \\
\hline Para-carcinoma tissue & 36 & $1.72 \pm 0.36$ & & $0.52 \pm 0.12$ & \\
\hline \multicolumn{6}{|l|}{ Age (years) } \\
\hline$<60$ & 15 & $1.28 \pm 0.52$ & \multirow[t]{2}{*}{$>0.05$} & $0.78 \pm 0.22$ & \multirow[t]{2}{*}{$>0.05$} \\
\hline$\geq 60$ & 21 & $1.33 \pm 0.45$ & & $0.75 \pm 0.26$ & \\
\hline \multicolumn{6}{|l|}{ Sex } \\
\hline Male & 28 & $1.22 \pm 0.49$ & \multirow[t]{2}{*}{$>0.05$} & $0.69 \pm 0.32$ & \multirow[t]{2}{*}{$>0.05$} \\
\hline Female & 8 & $1.26 \pm 0.55$ & & $0.72 \pm 0.29$ & \\
\hline \multicolumn{6}{|l|}{ Tumor size $(\mathrm{cm})$} \\
\hline$\leq 3$ & 20 & $1.69 \pm 0.13$ & \multirow[t]{2}{*}{$<0.01$} & $0.49 \pm 0.11$ & \multirow[t]{2}{*}{$<0.01$} \\
\hline$>3$ & 16 & $1.12 \pm 0.18$ & & $0.92 \pm 0.08$ & \\
\hline \multicolumn{6}{|l|}{ Lymph node metastasis } \\
\hline No & 8 & $1.76 \pm 0.06$ & \multirow[t]{2}{*}{$<0.01$} & $0.45 \pm 0.09$ & \multirow[t]{2}{*}{$<0.01$} \\
\hline Yes & 28 & $1.05 \pm 0.16$ & & $0.86 \pm 0.13$ & \\
\hline \multicolumn{3}{|l|}{ TNM stage } & \multirow{5}{*}{$<0.01$} & & \multirow[t]{5}{*}{$<0.01$} \\
\hline $\mathrm{I}$ & 3 & $1.42 \pm 0.06$ & & $0.42 \pm 0.05$ & \\
\hline II & 5 & $1.25 \pm 0.12$ & & $0.56 \pm 0.08$ & \\
\hline III & 25 & $1.03 \pm 0.18$ & & $0.85 \pm 0.13$ & \\
\hline IV & 3 & $0.96 \pm 0.05$ & & $0.86 \pm 0.07$ & \\
\hline
\end{tabular}

protein in cardiac carcinoma tissues had no correlation with the age and sex of patients with cardiac carcinoma $(\mathrm{P}>0.05)$, but was correlated with the tumor size, lymph node metastasis and TNM stage of cardiac carcinoma $(\mathrm{P}<0.01)$ (Table II). 


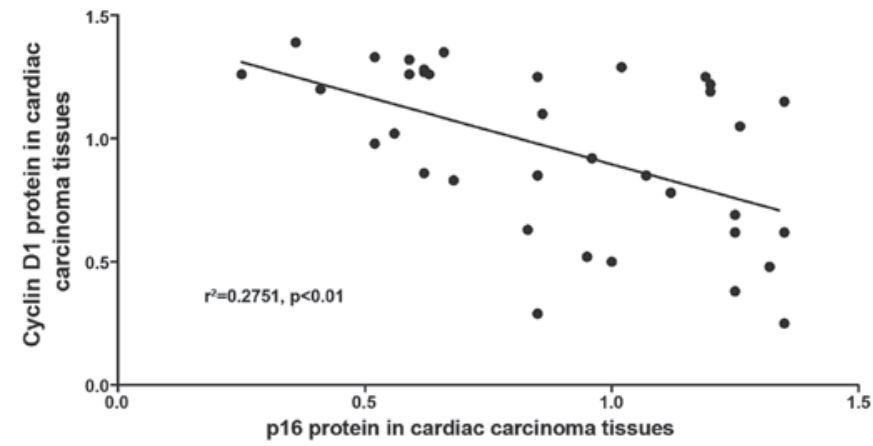

Figure 3. Correlation analysis between p16 and cyclin D1 proteins in cardiac carcinoma tissues. There is a negative correlation between p16 and cyclin D1 protein expressions in cardiac carcinoma tissues.

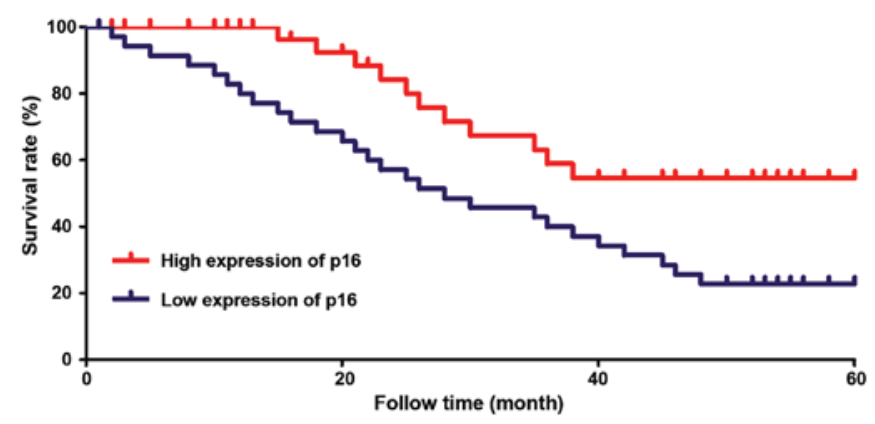

Figure 4. Survival curves of patients with high- and low-expression p16 in cardiac carcinoma tissues. The survival rate of patients with high expression of p16 is significantly higher than that of patients with low expression of p16.

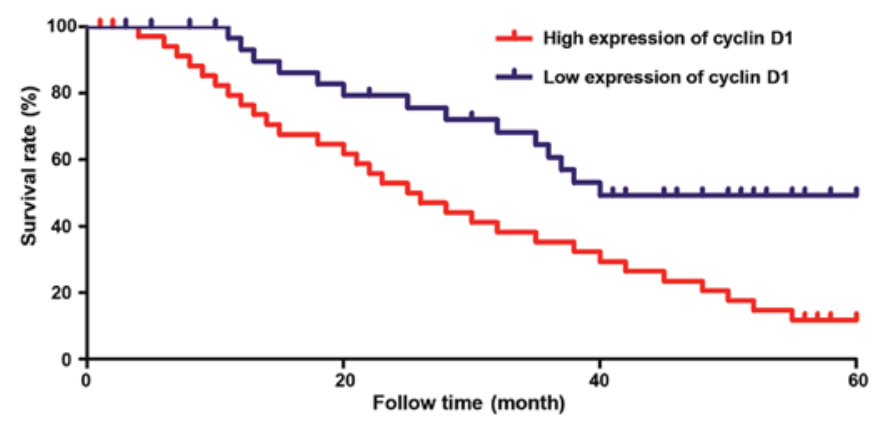

Figure 5. Survival curves of patients with high- and low-expression cyclin D1 in cardiac carcinoma tissues. The survival rate of patients with high expression of cyclin D1 is significantly lower than that of patients with low expression of cyclin D1.

Effects of p16 and cyclin D1 expression on the prognosis of patients with cardiac carcinoma. All the patients enrolled were grouped based on the relative expression levels of p16 and cyclin D1 proteins in cardiac carcinoma tissues, and followed up for 5 years. The survival data of patients were recorded, and the survival curve was drawn. According to Kaplan-Meier survival analysis, the survival rate of patients with high expression of p16 was obviously higher (58\%) than that (26\%) of patients with low expression of p16 $(\mathrm{P}<0.01)$, while the survival rate of patients with high expression of cyclin D1 was obviously lower $(19 \%)$ than that $(52 \%)$ of patients with low expression of cyclin $\mathrm{D} 1(\mathrm{P}<0.01)$ (Figs. 4 and 5).

\section{Discussion}

With the continuous development of medical technology, the 5-year survival time of tumor patients has also increased continuously, and the quality of life and health of patients have been greatly improved. However, the 5-year survival rate of patients with cardiac carcinoma is still approximately $30 \%$, and lymph node metastasis and postoperative recurrence of cardiac carcinoma are important factors seriously affecting the therapeutic effect on cardiac carcinoma $(12,13)$. Research evidence has demonstrated that cardiac carcinoma frequently occurs in high-incidence regions of gastric carcinoma and esophageal carcinoma, but neither incidence trend nor influencing factors of cardiac carcinoma are correlated with gastric carcinoma and esophageal carcinoma (14). Zhao et al (15) found that the p16/cyclin D1 signaling pathway plays an important role in glioma, which is involved in the regulation of the cell cycle. The decrease in p16 expression level or the increase in cyclin D1 expression level is closely related to the occurrence and development of glioma. p16 is a kind of cyclin kinase inhibitor playing an important role in inhibiting tumorigenesis. In case of deletion, methylation or point mutation of p16 gene, the p16 protein expression level will decline, and the number of abnormal cells will increase, leading to the tumor (16). According to the study of Zhou and Gu (17), the incidence rates of various tumors will be significantly increased after p16-knockout mice are exposed to various carcinogenic conditions. The expression level of cyclin D1, as a molecule playing an important role in the regulation of cell cycle, has been found to be obviously increased in a variety of tumors (18). Moreover, Cao et al (19) found that the expression level of cyclin D1 in gastric carcinoma tissues is significantly higher than that in para-carcinoma tissues, and the prognosis of patients with high expression of cyclin D1 is poorer.

In this study, the p16 gene and protein expression levels in carcinoma tissues and para-carcinoma tissues of 36 patients with cardiac carcinoma were detected. Results revealed that the p16 gene and protein expression levels in cardiac carcinoma tissues were significantly lower than those in para-carcinoma tissues. The p16 protein expression level in carcinoma tissues was significantly reduced with the enlargement of the cardiac carcinoma tumor and the increase of TNM stage. The above results strongly indicate that the p16 protein expression is closely related to the occurrence and development of cardiac carcinoma. Due to the particularity of cardiac carcinoma, lymph node metastasis is closely associated with the prognosis of patients. It was found that the p16 expression in carcinoma tissues of patients with lymph node metastasis of cardiac carcinoma was significantly lower than that in patients without lymph node metastasis of cardiac carcinoma. The 5-year follow up showed that the 5-year survival rate (58\%) of patients with high expression of p16 was significantly higher than that (26\%) of patients with low expression of p16, indicating that p16 is closely related to the prognosis of patients. Moreover, the correlation between p16 and cyclin D1 protein expression in cardiac carcinoma tissues was analyzed in this study, and results showed that p16 was negatively correlated with cyclin D1 in cardiac carcinoma tissues. Previous findings have demonstrated $(20,21)$ that there is a steady balance between p16 and cyclin D1 in normal human body, both of which jointly 
regulate the cell cycle. If the p16 expression is inhibited in the body, the cyclin D1 expression will be increased significantly, thereby leading to a tumor. At the same time, it was found in this study that the cyclin D1 expression was closely related to the tumor size, lymph node metastasis and TNM stage of cardiac carcinoma, and the 5-year survival rate $(19 \%)$ of patients with high expression of cyclin D1 was obviously lower than that $(52 \%)$ of patients with low expression of cyclin D1.

In conclusion, the expression of p16 and cyclin D1 is closely related to the incidence and prognosis of cardiac carcinoma, which is expected to be developed into important genes for predicting the incidence and prognosis of cardiac carcinoma.

\section{Acknowledgements}

Not applicable.

\section{Funding}

No funding was received.

\section{Availability of data and materials}

The datasets used and/or analyzed during the present study are available from the corresponding author on reasonable request.

\section{Authors' contributions}

HW performed PCR. HW and JW were responsible for western blotting. $\mathrm{HW}$ and BZ helped with the collection of clinicopathologic data and survival analysis. All authors read and approved the final manuscript.

\section{Ethics approval and consent to participate}

The study was approved by the Ethics Committee of The Second Affiliated Hospital of Zhengzhou University (Zhengzhou, China) and written informed consents were signed by the patients or the guardians.

\section{Patient consent for publication}

Not applicable.

\section{Competing interests}

The authors declare that they have no competing interests.

\section{References}

1. Wang HF and Lv JQ: The clinical evaluation of tegafur gimeracil oteracil combined with THP and DDP for second-line treatment of advanced cardiac carcinoma. Cell Biochem Biophys 72: 695-699, 2015

2. Chen G, Xu M, Chen J, Hong L, Lin W, Zhao S, Zhang G, Dan G and Liu S: Clinicopathological features and increased expression of toll-like receptor 4 of gastric cardia cancer in a high-risk Chinese population. J Immunol Res 2018: 7132868, 2018.

3. Lagergren F, Xie SH, Mattsson F and Lagergren J: Updated incidence trends in cardia and non-cardia gastric adenocarcinoma in Sweden. Acta Oncol 9: 1-6, 2018.
4. Padrão AI, Nogueira-Ferreira R, Vitorino R, Carvalho D, Correia C, Neuparth MJ, Pires MJ, Faustino-Rocha AI, Santos LL, Oliveira PA, et al: Exercise training protects against cancer-induced cardiac remodeling in an animal model of urothelial carcinoma. Arch Biochem Biophys 645: 12-18, 2018.

5. Xie CM, Lin XT, Wu D, Tan Y, Cheng CHK and Zhang J: Cardiac glycoside bufalin blocks cancer cell growth by inhibition of Aurora A and Aurora B activation via PI3K-Akt pathway. Oncotarget 9: 13783-13795, 2018.

6. Xi S, Payabyab EC, Straughan DM, Reardon ES, Zhang M, Hong JA, Ripley RT, Hoang CD and Schrump DS: Asbestos induces epigenetic repression of ras association domain-containing protein 1, p16 kinase 4a inhibitor, and p14 alternative reading frame in normal human mesothelial cells. Ann Am Thorac Soc 15 (Suppl 2): S123, 2018.

7. Liu JQ, Zhang QH and Wang ZL: Clinicopathological significance of p16, cyclin D1, Rb and MIB-1 levels in skull base chordoma and chondrosarcoma. World J Otorhinolaryngol Head Neck Surg 1: 50-56, 2015.

8. Dreyer JH, Hauck F, Barros MHM and Niedobitek G: pRb and cyclinD1 complement p16 as immunohistochemical surrogate markers of HPV infection in head and neck cancer. Appl Immunohistochem Mol Morphol 25: 366-373, 2017.

9. Feng Z, Chen J, Wei H, Gao P, Shi J, Zhang J and Zhao F: The risk factor of gallbladder cancer: Hyperplasia of mucous epithelium caused by gallstones associates with p16/CyclinD1/CDK4 pathway. Exp Mol Pathol 91: 569-577, 2011.

10. Pu X, Zhu L, Fu Y, Fan Z, Zheng J, Zhang B, Yang J, Guan W, Wu H, Ye Q, et al: Companied P16 genetic and protein status together providing useful information on the clinical outcome of urinary bladder cancer. Medicine (Baltimore) 97: e0353, 2018.

11. Livak KJ and Scmittgen TD: Analysis of relative gene expression data using real-time quantitative PCR and the 2(-Delta Delta C(T)) method. Methods 25: 402-408, 2001.

12. Ong G, Brezden-Masley C, Dhir V, Deva DP, Chan KKW, Chow CM, Thavendiranathan D, Haq R, Barfett JJ, Petrella TM, et al: Myocardial strain imaging by cardiac magnetic resonance for detection of subclinical myocardial dysfunction in breast cancer patients receiving trastuzumab and chemotherapy. Int J Cardiol 261: 228-233, 2018.

13. Boisclair Lachance JF, Webber JL, Hong L, Dinner AR and Rebay I: Cooperative recruitment of Yan via a high-affinity ETS supersite organizes repression to confer specificity and robustness to cardiac cell fate specification. Genes Dev 32: 389-401, 2018.

14. Chen Y, Kang Y, Hong L and Yao H: Hypoglycemia caused by co-secretion of insulin from lung tumor and cardia cancer: First case report. Sao Paulo Med J: Nov 17, 2017 (Epub ahead of print).

15. Zhao X, Song T, He Z, Tang L and Zhu Y: A novel role of cyclinD1 and p16 in clinical pathology and prognosis of childhood medulloblastoma. Med Oncol 27: 985-991, 2010.

16. Prigenzi KCK, Heinke T, Salim RC and Focchi GRA: Dual p16 and Ki-67 expression in liquid-based cervical cytological samples compared to Pap cytology findings, biopsies, and HPV testing in cervical cancer screening: A diagnostic accuracy study. Acta Cytol 62: 104-114, 2018.

17. Zhou N and Gu Q: Prognostic and clinicopathological value of p16 protein aberrant expression in colorectal cancer: A PRISMA-compliant Meta-analysis. Genes Nutr 5: 63-75, 2015.

18. Tang Y, Berlind J and Mavila N: Inhibition of CREB binding protein-beta-catenin signaling down regulates CD133 expression and activates PP2A-PTEN signaling in tumor initiating liver cancer cells. Cell Commun Signal 16: 9, 2018.

19. Cao L, Liu Y, Wang D, Huang L, Li F, Liu J, Zhang C, Shen Z, Gao Q, Yuan W, et al: MiR-760 suppresses human colorectal cancer growth by targeting BATF3/AP-1/cyclinD1 signaling. J Exp Clin Cancer Res 37: 83, 2018.

20. Fu ZJ, Ma ZY, Wang QR, Lei DP, Wang R, Liu CX and Pan XL: Overexpression of CyclinD1 and underexpression of p16 correlate with lymph node metastases in laryngeal squamous cell carcinoma in Chinese patients. Clin Exp Metastasis 25: 887-892, 2008.

21. Liu T, Niu Y, Feng Y, Niu R, Yu Y, Lv A and Yang Y: Methylation of $\mathrm{CpG}$ islands of p16(INK4a) and cyclinD1 overexpression associated with progression of intraductal proliferative lesions of the breast. Hum Pathol 39: 1637-1646, 2008.

This work is licensed under a Creative Commons Attribution-NonCommercial-NoDerivatives 4.0 International (CC BY-NC-ND 4.0) License. 